\title{
Fotossíntese: utilização de um modelo didático interativo para o processo de ensino e aprendizagem
}

\author{
Photosynthesis: an interactive didactic model's use to the learning and teaching process
}

\author{
Vanessa Liesenfeld ${ }^{1 *}$, Vanessa Cristina Arfelli ${ }^{1}$, Thomas Machado da Silva ${ }^{1}$, Juliana Moreira Prudente de \\ Oliveira $^{1}$
}

\author{
${ }^{1}$ Universidade Estadual do Oeste do Paraná (UNIOESTE), Campus Cascavel-PR \\ *e-mail: vane lie@hotmail.com
}

\section{Resumo}

A fotossíntese é um processo complexo que envolve a realização de várias reações que, muitas vezes, tornam este conteúdo de difícil compreensão para os alunos. Neste trabalho, objetivou-se investigar se um modelo didático interativo, confeccionado com materiais simples, poderia facilitar a compreensão e aprendizado dos alunos referente ao tema fotossíntese. Para tanto, inicialmente foi solicitado aos alunos de uma turma do $1^{\circ}$ ano do Ensino Médio de um colégio público estadual do oeste do Paraná que esquematizassem o que sabiam sobre fotossíntese e respondessem a um questionário. Verificou-se que muitas das concepções prévias dos alunos traziam conceitos generalistas ou errôneos, como a ideia de que a fotossíntese é o processo de respiração das plantas, e que o $\mathrm{O}_{2}$ é oriundo do $\mathrm{CO}_{2}$, e não da foto-oxidação da água. Estas concepções foram importantes para planejar a abordagem do tema, que foi realizada de forma expositiva e dialogada, utilizando um modelo didático interativo para evidenciar as explicações, e em seguida, um novo questionário foi respondido pelos alunos. Concluiu-se que o uso do modelo didático interativo foi eficiente, pois ajudou a consolidar conceitos corretos, ao mesmo tempo em que introduziu novos conceitos e abalou as relações equivocadas.

Palavras-chave: Ensino de Ciências e Biologia, Energia Solar, Clorofila.

\begin{abstract}
Photosynthesis is a complex process that involves the implementation of several reactions which, many times, makes this content difficult for students to understand. The objective of this study was to investigate if an interactive didactic model, crafted with simple materials, could facilitate the understanding and learning of students on photosynthesis. Initially students of first year high school class from a public school Western of Paraná were asked to diagram what they knew about photosynthesis and respond to a questionnaire. It was concluded that many of the students' prior concepts were general or inaccurate, such as the idea of photosynthesis being the process of respiration in plants, and $\mathrm{O}_{2}$ coming from the $\mathrm{CO}_{2}$, not from the photooxidation of water. These prior conceptions were important for planning the approach to the subject. The process of photosynthesis was then covered in lecture and dialogued, using the interactive didactic model to highlight the explanations. A new questionnaire was completed by the students, and concluded that the use of the interactive didactic model was efficient, since it helped to consolidate correct concepts and simultaneously, introduced new ones as well it shook the equivocal relations.
\end{abstract}

Keywords: Science and Biology Teaching, Solar Energy, Chlorophyll. 


\section{Introdução}

A manutenção da vida necessita de constante fornecimento de energia. Plantas e animais a adquirem de maneiras diferentes. Os animais obtêm dos alimentos os compostos orgânicos, que são utilizados em grande parte na respiração, para obtenção de energia química na forma de ATP. As plantas possuem clorofila, pigmento capaz de absorver energia em forma de luz a partir do sol, convertendo-a em energia química, que é armazenada nas ligações covalentes dos carboidratos através do processo chamado fotossíntese. Esses carboidratos também serão utilizados pela planta na respiração, para a obtenção de ATP. Assim, dizemos que as plantas são autotróficas, ou seja, produzem seu próprio alimento, enquanto os animais são heterotróficos. Fotossíntese e respiração são processos complementares que ocorrem em nosso planeta e de maneira geral, há um balanço entre os dois [1].

A fotossíntese é um dos processos biológicos mais importantes do planeta, pois dá início à transformação da energia na biosfera. Essa energia é transferida por meio da cadeia alimentar, e esse processo evidencia a interdependência entre os seres heterotróficos e autotróficos [2].

No Ensino Médio os temas fotossíntese e respiração envolvem conceitos fundamentais para o ensino de biologia, possibilitando uma visão abrangente dos mecanismos e dos ciclos de vida dos seres vivos, bem como suas relações na cadeia alimentar, evolução, metabolismo energético, entre outros. Porém, muitos alunos oriundos do Ensino Fundamental têm ideias errôneas sobre o assunto e cabe ao professor trabalhar conceitos científicos corretos, podendo utilizar recursos que auxiliem nesse processo, como os modelos didáticos [3].

O desempenho escolar dos alunos tem sido preocupante $\mathrm{e}$ isto se deve principalmente à utilização de uma abordagem tradicional por grande parte dos professores [4]. O principal desafio encontrado para superar as dificuldades e deficiências na educação é a adequação na formação de professores, pois dificilmente um professor que tenha vivenciado na sua formação acadêmica uma didática baseada no modelo tradicional poderá desenvolver uma didática inovadora com seus alunos [5].

$\mathrm{Na}$ tentativa de superar essas dificuldades da formação docente, "pesquisadores na área, oriundos de diferentes contextos, e até as novas diretrizes para a formação de professores no Brasil indicam a necessidade de implementação de uma perspectiva investigativa na formação inicial" [5]. Se houver a inserção, na formação de professores, de práticas de caráter investigativo, estas podem impulsionar mudanças na postura e 
atitude dos acadêmicos quando docentes. Mas para isso, é necessário abandonar uma formação voltada a uma visão simplista do processo de ensino e aprendizagem do aluno na prática profissional [6].

Outro problema encontrado na educação é a dificuldade que muitos professores de biologia têm de planejar e organizar o conteúdo a ser ensinado de maneira mais compreensível para os alunos. Uma alternativa para superar esse problema é a utilização de modelos didáticos com estruturas tridimensionais, que possibilitam maior facilidade ao ensino e aprendizagem de conteúdos [7].

A utilização de modelos biológicos com estruturas tridimensionais e coloridas são facilitadores do aprendizado, pois, além do aspecto visual, a manipulação e até mesmo a construção desses modelos pelos próprios alunos desperta neles a preocupação com os detalhes intrínsecos dos modelos e, dessa forma, eles passam a revisar e assim compreender o conteúdo que está sendo trabalhado [8].

O modelo didático é um mediador entre a realidade e o pensamento, sendo um recurso importante para o desenvolvimento técnico e fundamentação científica do ensino visando o abandono de uma formação empírica e particular. O modelo didático proporciona a experimentação e a problematização, atividades de raciocínio que enriquecem o processo de aprendizagem [9].

Cientes da necessidade de mudanças nas práticas pedagógicas para melhorar o processo de ensino e aprendizagem, e baseados em experiências pessoais na compreensão do conteúdo, buscou-se confeccionar um modelo didático interativo sobre fotossíntese, utilizá-lo em aulas de biologia, e investigar qual a sua contribuição na compreensão dos alunos sobre o tema.

\section{Planejamento, confecção e funcionamento do modelo didático interativo}

O planejamento para a utilização do modelo didático interativo em sala de aula, bem como a sua construção e implementação, se deu em duas disciplinas da área de ensino de Ciências e Biologia do Curso de Ciências Biológicas - Licenciatura de uma Universidade estadual do oeste do Paraná. Essas disciplinas são organizadas de forma a possibilitarem que os alunos da graduação tenham contato com a realidade escolar ainda no segundo e terceiro ano do curso, atendendo, entre outros objetivos do curso, à resolução CNE/CP 1/2002 [10]. Esta resolução afirma que "a prática, na matriz curricular, não poderá ficar reduzida a um espaço isolado, que a restrinja ao estágio, desarticulado do restante do curso" e deve "estar presente desde o início do curso e permear toda a 
formação do professor", sendo trabalhada em todas as disciplinas, sejam pedagógicas ou não.

Para que essas disciplinas possibilitem o trabalho com a dimensão prática, os alunos inicialmente elaboram um projeto que, posteriormente, é implementado em uma escola/colégio. O projeto que deu origem a este trabalho intitulava-se: "Abordando a fotossíntese no Ensino Médio" e foi implementado em quatro aulas para uma turma com 31 alunos do $1^{\circ}$ ano do Ensino Médio de um colégio estadual da região oeste do Paraná. Este projeto envolvia a construção de um modelo didático interativo sobre fotossíntese, o qual foi planejado com o objetivo de proporcionar aos alunos a visualização dos eventos que constituem a fotossíntese, como o local em que ela ocorre, por exemplo. A fim de deixar clara a importância da energia solar na fotossíntese e desse processo como um todo para manutenção da vida na Terra, o modelo desenvolvido relacionava teoria e prática, de forma a facilitar a assimilação deste conteúdo tido como abstrato por muitos alunos.

Para tanto, o modelo foi confeccionado com materiais simples e de fácil disponibilidade, a saber: um painel vertical em isopor de $1 \mathrm{~m} \times 1 \mathrm{~m}$; tinta guache; mangueira 3/8 transparente; cola de isopor e cola branca; miçangas vermelhas e verdes; palito de dente e de churrasco; papel cartão; canetinhas e sacola plástica.

O isopor é a base do modelo, e nele foi representada a membrana de um tilacoide. Desse isopor foi retirada uma camada, com auxílio de estiletes, e construiu-se um circuito de mangueira 3/8 transparente que representaria o caminho percorrido pelos elétrons e íons hidrogênio (representados pelas miçangas verdes e vermelhas, respectivamente) durante as reações da etapa fotoquímica. Os fotossistemas e complexos presentes nesse processo foram representados com papel cartão. A plastocianina (carreadora de elétrons) foi representada por palitos de churrasco que ora impediam a passagem das miçangas (elétrons), ora permitiam a sua passagem. A ATPsintase foi representada com a junção de dois pedaços de papel cartão em forma de catavento. Atrás do isopor foram colocadas algumas sacolas plásticas em locais específicos da saída das miçangas.

O ciclo de Calvin, fase de fixação do carbono, foi esquematizado com figuras que representavam os átomos e moléculas envolvidos nas reações. Representou-se ainda a fase fotoquímica e a fase bioquímica da fotossíntese através das cores verde e preta, respectivamente. Apresenta-se na Figura 1 o modelo didático interativo, bastante colorido e dinâmico: 


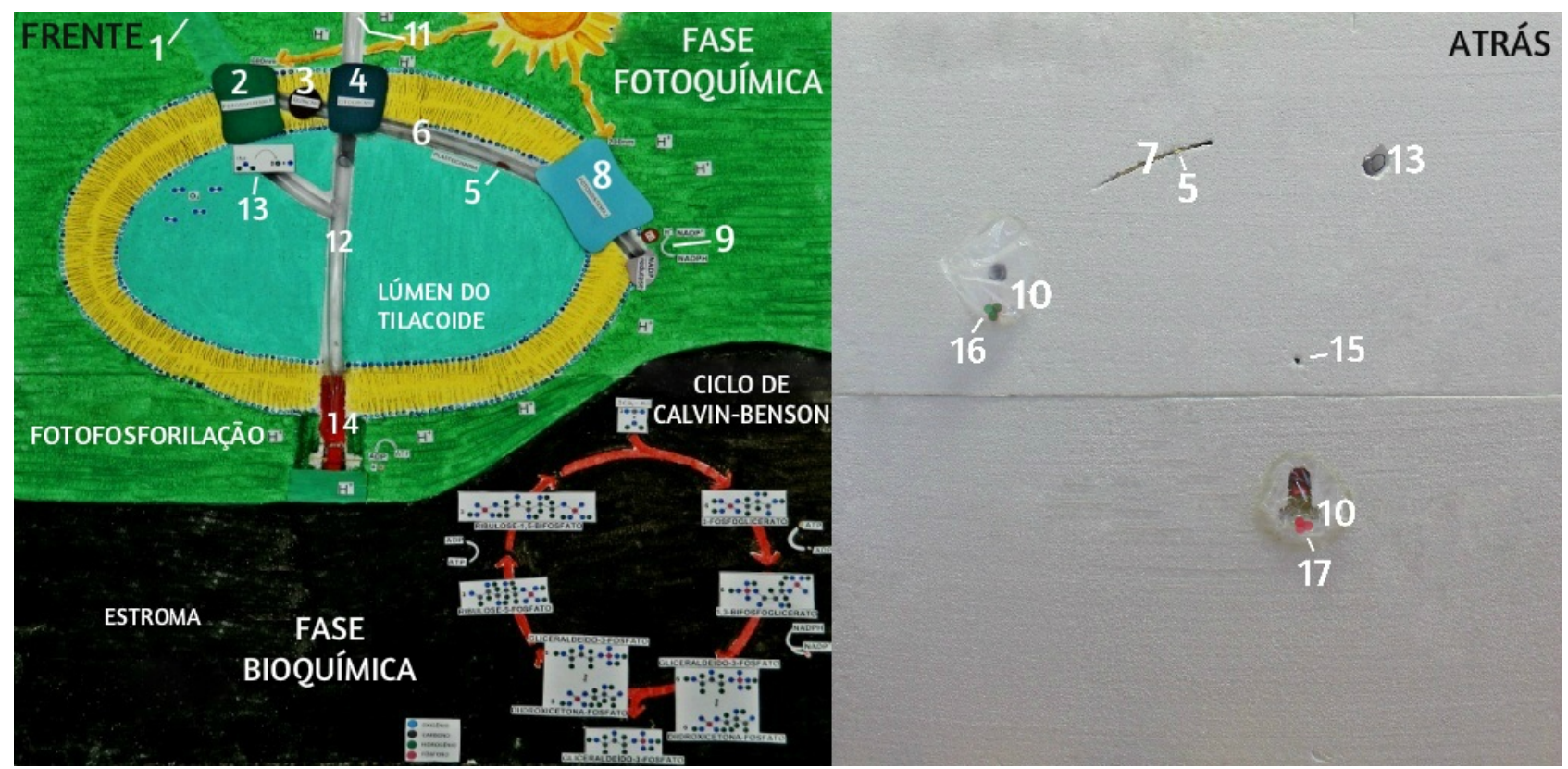

Figura 1. Modelo didático interativo representando as etapas da fotossíntese.

Para que os processos da fase fotoquímica da fotossíntese sejam demonstrados no modelo didático é necessária intervenção manual. Assim, conforme a Figura 1, os elétrons perdidos após a excitação das moléculas de clorofila pelo sol são representados por miçangas verdes (16), que devem ser colocadas através da mangueira transparente, por uma abertura superior (1). Os elétrons partem do fotossistema II (2), passando para a quinona (3), citocromo C (4) e param na plastocianina (5), que está aderida a um palito de madeira impedindo a passagem na mangueira (6), e que deve ser movido por trás do modelo, pelo sulco no isopor (7), de modo a carregar os elétrons (um de cada vez). Então, eles seguirão o caminho através da mangueira, passando da plastocianina para o fotossistema I (8). No fotossistema I, os elétrons da plastocianina reduzem a clorofila, que foi oxidada pela luz solar. Os elétrons perdidos pela clorofila do fotossistema I (também representados pelas miçangas verdes) passam pela ferredoxina (9) e numa reação catalisada pela enzima ferredoxina-NADPredutase os elétrons reduzem NADP+ a NADPH, saindo pela parte de trás do painel, onde estão as caçapas de sacola plástica (10), impedindo que as miçangas caiam e representando o fim do percurso.

Quando os elétrons passam pelo citocromo C (4), íons hidrogênio $\left(\mathrm{H}^{+}\right)$são bombeados para dentro da membrana do tilacoide. Esses $\mathrm{H}^{+}$, representados por miçangas vermelhas (17) são colocados manualmente através de uma abertura em outro pedaço de mangueira (11), e confluem para um circuito comum (12), onde desembocam também os $\mathrm{H}^{+}$liberados pela quebra da molécula de água, também colocados manualmente (13). Todos os íons hidrogênio que têm como destino a ATPsintase (14) ficam retidos nessa mangueira por um palito de madeira (15) apenas para coordenar o 
tempo em que os processos acontecem, com o objetivo de facilitar a explicação teórica do que acontece em cada etapa. Quando o palito é retirado todos os $\mathrm{H}^{+}$confluem para a ATPsintase que, como uma catraca, gira, exemplificando a formação de ATP a partir de $\mathrm{ADP}+\mathrm{Pi}$, utilizando a energia do gradiente de íons hidrogênio. As miçangas confluem também para uma caçapa no lado posterior do painel (10).

Como dito anteriormente, a fase bioquímica foi representada pelas moléculas e seus átomos, mas apenas com esquemas e figuras.

\section{Implementação do modelo didático, coleta e análise dos dados}

A implementação do modelo didático envolveu as seguintes etapas:

- Elaboração, pelos alunos, de esquema em folha sulfite, contendo desenhos e/ou escrita, de maneira a abordar o que lembravam sobre fotossíntese;

- Aplicação de questionário contendo perguntas relacionadas ao processo da fotossíntese;

- Aula expositiva e dialogada, realizada com o auxílio de outro modelo didático, também produzido em isopor, com a figura de uma célula vegetal contendo sua estrutura e todas as suas organelas bem identificadas, possibilitando aos alunos uma visão geral do local onde ocorre a fotossíntese e, dessa forma, a contextualização do assunto. Após, foi utilizado o modelo didático interativo, que representa todos os processos fotossintéticos que ocorrem na membrana do tilacoide de um cloroplasto, evidenciando o local específico da fotossíntese e permitindo expor detalhadamente aos alunos a maquinaria fotossintética;

- Aplicação do segundo questionário com questões relacionadas ao processo de fotossíntese.

Portanto, fizeram parte da coleta de dados os esquemas realizados pelos alunos e os questionários respondidos. Assim, a investigação trata-se de uma pesquisa quantiqualitativa, na qual o foco foi investigar quais os conceitos prévios dos alunos, bem como quais foram assimilados. A investigação quanti-qualitativa visa obter um conhecimento mais amplo ou validar as descobertas alcançadas pela abordagem quantitativa, qualitativa ou por ambas [11]. A combinação da abordagem quantitativa e da qualitativa pode resultar na confirmação mútua dos resultados quantitativos e qualitativos, ou então na complementação dos resultados obtidos nas duas abordagens, ou ainda, gerar resultados divergentes e contraditórios, o que dá mais amplitude à discussão [11]. 
Para analisar os dados presentes nos esquemas foi utilizada a análise documental, a qual complementa informações já obtidas por outras técnicas ou demonstra novos aspectos sobre o tema em questão [12].

\section{Resultados e Discussão}

Inicialmente foi solicitado aos alunos que esquematizassem em uma folha de papel seus conhecimentos sobre o tema fotossíntese, e os mesmos utilizaram desenhos, frases e/ou pequenos textos. Os dados provenientes foram sintetizados em conceitos/palavraschave (eixo $\mathrm{x}$ ) que apareceram com mais frequência (eixo y, em unidades) nos esquemas dos alunos, os quais podem ser visualizados na Figura 2.

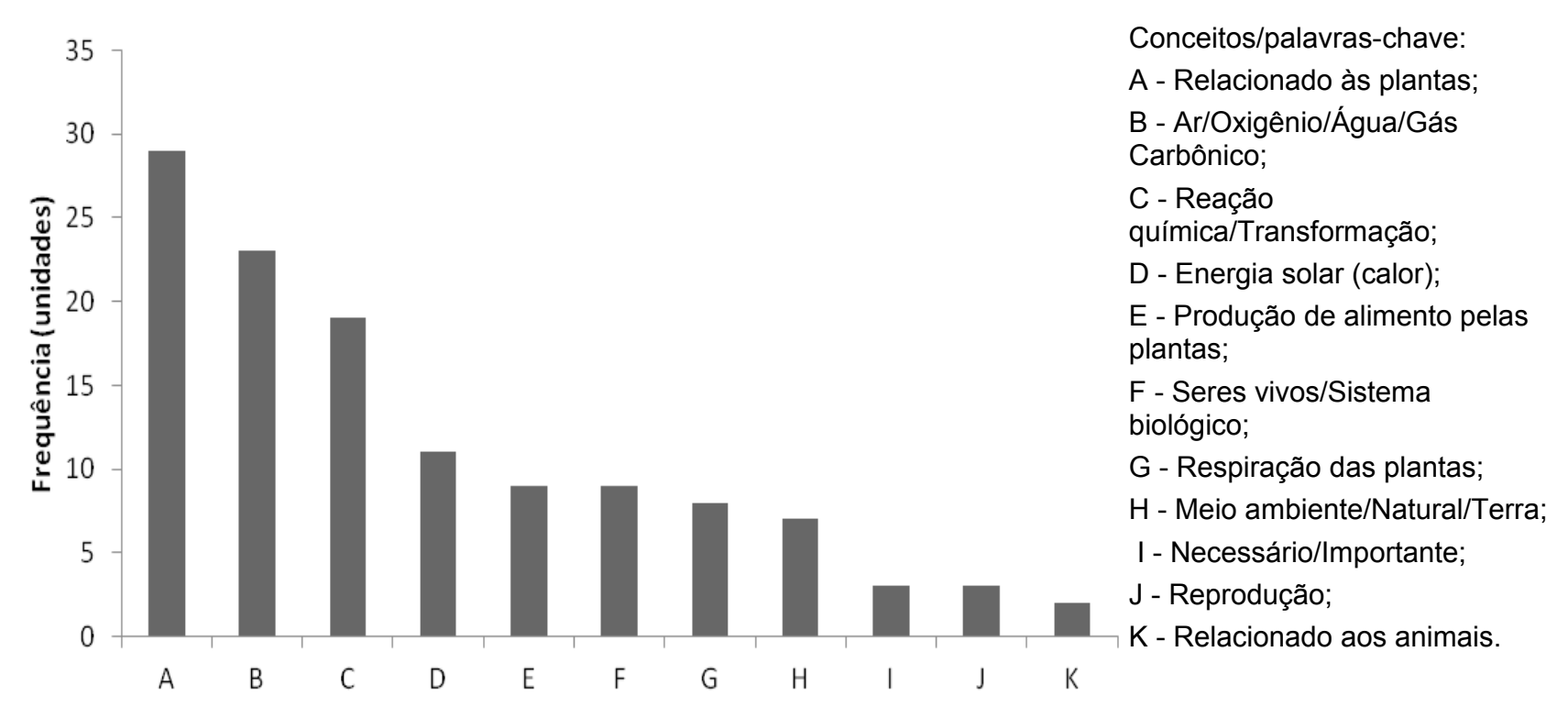

Figura 2. Concepções prévias dos alunos sobre fotossíntese.

Ao analisar esses esquemas, observou-se que a grande maioria dos alunos relaciona a fotossíntese às plantas $(A)$, sendo este o conceito mais evidente dentre todos. Os alunos não mencionaram outros organismos fotossintetizantes, como algas e certas bactérias, o que pode ser justificado pelo fato destes organismos não serem tão comuns no cotidiano deles, ou pela ênfase dada às plantas na abordagem sobre fotossíntese no Ensino Fundamental. Este aspecto é evidenciado na Figura 3. 


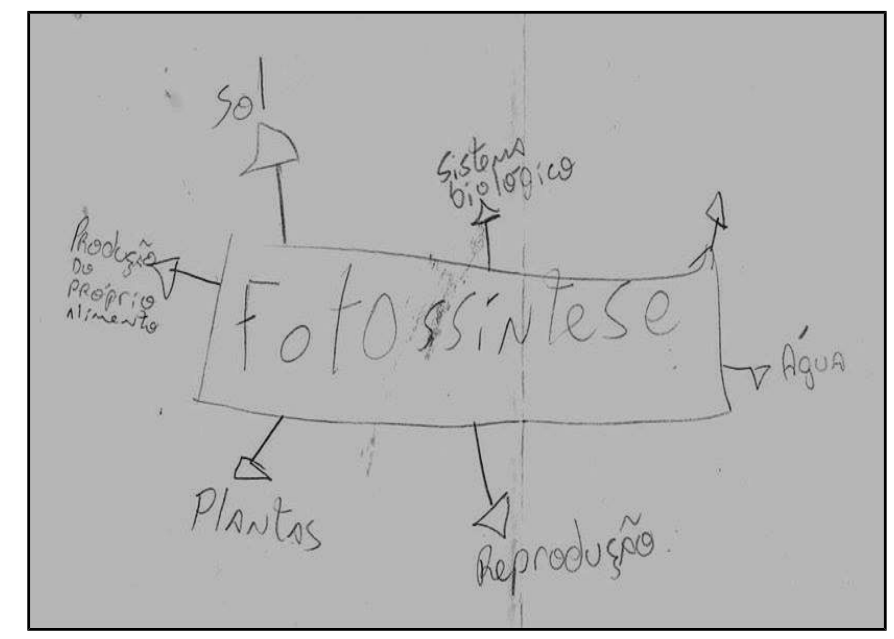

Figura 3. Esquema elaborado por um aluno representando, principalmente, a ideia da maioria de que fotossíntese é um processo relacionado às plantas.

Outros conceitos frequentemente presentes nos esquemas foram: a relação da fotossíntese com ar/oxigênio, água e gás carbônico (B), e a noção de reação química e transformação $(\mathrm{C})$ dos reagentes em produtos. Ficou claro que a reação química clássica da fotossíntese foi lembrada pelos alunos, porém apontaram somente um dos produtos resultantes: o oxigênio. Com isso, pode-se inferir que interpretam a fotossíntese como essencial para a produção de oxigênio principalmente para os seres humanos, revelando uma visão antropocêntrica. Grande parte dos alunos não compreende a fotossíntese como o processo responsável pela produção de composto orgânico para os seres autotróficos fotossintetizantes. Visualiza-se também que 19 alunos associaram fotossíntese com um evento químico de transformação. Logo, têm a noção de que há uma transformação, possivelmente por terem estudado fotossíntese em séries anteriores, mas não sabem o quê se transforma em quê, e nem como isso ocorre, por ainda não terem estudado sobre átomos e suas propriedades na química, ou por possíveis falhas anteriores no processo de ensino e aprendizagem. Na Figura 4 percebe-se que o aluno relaciona a fotossíntese à transformação do gás carbônico em oxigênio, reforçando a ideia de que o oxigênio vem do $\mathrm{CO}_{2}$ e não da água. 


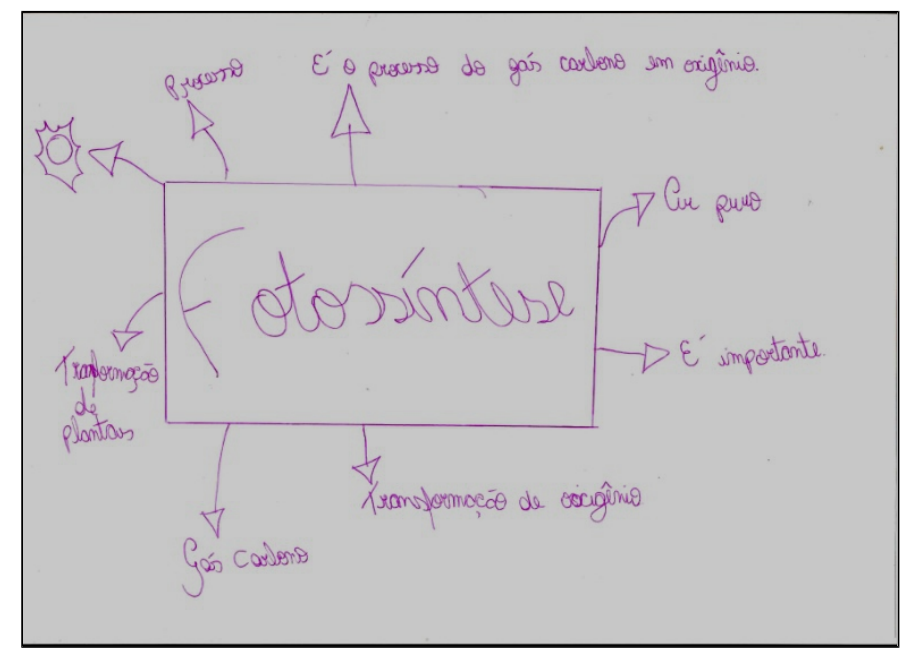

Figura 4. Esquema elaborado por um aluno representando seu conhecimento sobre fotossíntese, enfatizando principalmente o conceito "transformação".

Onze alunos relacionaram corretamente o conceito de energia solar (D) ao processo fotossintético, porém a maioria desconhece que a energia solar é armazenada em forma de energia química pelas plantas e que através da cadeia alimentar essa energia é transferida e possibilita a vida na Terra. É comum entre os alunos o pensamento de que a luz solar não é necessária para a planta, nem está relacionada à fotossíntese, ou que serve apenas para manter a planta aquecida [13].

Poucos alunos associaram o tema fotossíntese com os conceitos de alimentação $(E)$, seres vivos $(F)$, respiração $(G)$ e meio ambiente $(H)$. Assim, apenas alguns alunos indicaram que a fotossíntese é o processo que produz o alimento da planta, mas nenhum menciona a formação de carboidratos. Os conceitos de respiração e seres vivos podem ter sido evocados pelos alunos devido ao enfoque dado à fotossíntese como responsável pela produção de oxigênio para a respiração de outros seres vivos, como já mencionado. O conceito de meio ambiente pode estar relacionado à crença de que as plantas "purificam o ar", como aparece em outras palavras relacionadas. Ainda, alguns conceitos, como a ideia de que a fotossíntese é necessária e importante (I), ou relacionado à reprodução das plantas $(\mathrm{J})$ e relacionado aos animais $(\mathrm{K})$, apareceram possivelmente por se relacionarem à biologia de um modo geral, e não à fotossíntese especificamente.

Os alunos também responderam a um questionário prévio, contendo questões básicas que abordavam o tema fotossíntese. Apresenta-se no Quadro 1 as ideias centrais de cada questão e os dados obtidos: 
Quadro 1. Dados obtidos no questionário inicial.

\begin{tabular}{|c|l|c|c|c|}
\hline \multicolumn{2}{|c|}{ Assuntos abordados nas questões sobre fotossíntese } & Acertos & Erros & Não sei \\
\hline 1 & Processo responsável pela liberação de $\mathrm{O}_{2}$ na atmosfera & 19 & 7 & 5 \\
\hline 2 & Relação do organismo com o processo de obtenção de alimento & 13 & 9 & 9 \\
\hline 3 & Seres vivos que realizam a fotossíntese & 7 & 16 & 8 \\
\hline 4 & Reagentes da fotossíntese & 12 & 10 & 9 \\
\hline 5 & Composto orgânico produzido pela fotossíntese & 7 & 15 & 9 \\
\hline 6 & Organela onde ocorre a fotossíntese & 8 & 11 & 12 \\
\hline 7 & Pigmento que absorve luz & 14 & 9 & 8 \\
\hline 8 & Importância da luz solar para a vida na Terra & 11 & 19 & 1 \\
\hline 9 & Relação entre $\mathrm{O}_{2}$ e $\mathrm{CO}_{2}$ na fotossíntese & 6 & 20 & 5 \\
\hline
\end{tabular}

Com relação ao processo responsável pela liberação de $\mathrm{O}_{2}$ na atmosfera (primeiro assunto), 19 alunos indicaram a resposta correta, sendo a questão com mais acertos, o que corrobora também com um dos conceitos/palavras-chave mais apontados nos esquemas, ou seja, a citação do oxigênio. De acordo com o trabalho de Bandeira [13], é comum entre os alunos o pensamento de que o objetivo da fotossíntese é produzir oxigênio. Outra concepção comum é a de que as plantas produzem oxigênio para os seres humanos, como demonstra o relato de um aluno para o trabalho de Souza e Almeida [14]: "(...) sei que é o processo no qual as plantas absorvem gás carbônico e liberam oxigênio, tendo uma enorme importância aos seres humanos". A maioria de acertos nessa questão foi esperada, uma vez que no Ensino Fundamental essa é a ideia mais enfatizada, pois “(...) [a fotossíntese] é abordada de forma bastante superficial, geralmente nas séries iniciais quando se fala da origem do oxigênio" [15].

Em relação ao segundo assunto do Quadro 1, a questão discutiu a forma de obtenção de alimento por seres heterotróficos e autotróficos, solicitando aos alunos que assinalassem a alternativa que possuía um ser autotrófico e o nome do processo de obtenção de alimento. A maioria das marcações (13) deu-se sobre a alternativa que trazia os vegetais como o ser autotrófico e fotossíntese como o processo de obtenção de alimento, 9 marcações se deram em alternativas erradas e 9 alunos não souberam responder. A frase "Fotossíntese é o processo pelo qual as plantas produzem seu próprio alimento" é a mais utilizada para introduzir cientificamente o assunto no ensino de ciências [16], e evidencia que as respostas dos alunos nesse trabalho se baseiam nos conteúdos que viram em séries anteriores, destacando a importância do trabalho no Ensino Fundamental. É nessa fase que ocorre o primeiro contato com o conteúdo científico e a informação assimilada pode acompanhar o aluno por toda a vida escolar, por 
isso não deve ser errônea. A quantidade de erros e não sei pode estar relacionada ao desconhecimento do que é um ser autotrófico.

A abordagem do terceiro assunto do Quadro 1 remetia aos diferentes grupos de organismos fotossintetizantes - plantas, algas, cianobactérias e proclorófitas. A minoria dos alunos (7) assinalou a alternativa correta, que indicava todos esses organismos como fotossintetizantes, enquanto a grande maioria (16) marcaram alternativas que traziam essas bactérias como seres não fotossintetizantes, e vários alunos (8) não souberam responder. Esse resultado demonstra claramente que praticamente todo o conteúdo de fotossíntese abordado no Ensino Fundamental está voltado somente às plantas, como descrito na maioria dos livros didáticos. A educação científica está associada a livros didáticos que podem reproduzir currículos defasados e deixar lacunas no processo de ensino e aprendizagem [17]. É preciso transcender a informação contida neles. Muitas vezes, ao simplificar o conteúdo teórico com o objetivo de facilitar o entendimento, os livros trazem ideias superficiais que contribuem negativamente para as concepções alternativas dos alunos e isso se torna particularmente preocupante quando o professor utiliza o livro didático como único material de apoio.

No quarto assunto abordado, os alunos deveriam indicar a alternativa que representava os reagentes utilizados na fotossíntese. Mesmo possuindo um restrito conhecimento sobre química, observou-se que a alternativa correta foi a mais assinalada: 12 alunos marcaram a alternativa que mencionava as substâncias $\mathrm{CO}_{2}$ e $\mathrm{H}_{2} \mathrm{O}$ na presença de luz e clorofila; 10 alunos marcaram alternativas erradas e 9 alunos não souberam responder. A maioria de acertos pode estar relacionada com a forma como a fotossíntese é apresentada inicialmente para os alunos: como equação, que deve ser decorada. Apesar de a equação ocorrer também nos esquemas feitos pelos alunos, possivelmente muitos deles não compreenderam verdadeiramente seu significado, sendo muito frequente pensarem que o oxigênio liberado é proveniente do $\mathrm{CO}_{2}$ e não da fotooxidação da água, conforme apontado também pela literatura [16].

No quinto assunto do Quadro 1, a questão propunha aos alunos assinalar a alternativa que representasse o produto orgânico resultante da fotossíntese e qual a classe desse produto na química orgânica. Sete alunos marcaram a alternativa correta (glicose, classe dos carboidratos), porém, 15 marcaram alternativas erradas e 9 alunos não souberam responder. O alto índice de erros deve-se ao desconhecimento do principal produto da fotossíntese, pois em muitas abordagens sobre o tema enfatiza-se somente a liberação de $\mathrm{O}_{2}$ como produto. Ao mesmo tempo em que os alunos sabem que através da fotossíntese as plantas produzem seu próprio alimento, não sabem exatamente que 
alimento é esse, nem como é utilizado por ela. No trabalho de Bandeira [13], uma das concepções alternativas apresentadas pelos alunos é: "A fotossíntese não produz carboidrato". Nesse caso e em muitos outros, a compreensão do significado da palavra carboidrato transforma-se em uma barreira para o entendimento do conteúdo, evidenciando quão importante é trabalhar os conceitos de forma correta.

O sexto assunto abordava as organelas da célula vegetal, requerendo aos alunos que marcassem qual a organela em que ocorre o processo da fotossíntese. Somente 8 alunos marcaram a alternativa correta (cloroplasto), 11 marcaram alternativas erradas e 12 não souberam responder. A grande quantidade de erros e de alunos que não souberam responder revela que o assunto célula vegetal é tratado superficialmente durante o ensino. O trabalho de Silveira et al. [18] revela que, de 161 alunos, apenas 13 souberam esquematizar uma célula vegetal e apenas 57 souberam identificá-la. Os resultados são preocupantes e revelam necessidade de maior atenção a este conteúdo, sendo importantíssimo para o entendimento da fotossíntese e outros processos que ocorrem nas plantas.

O sétimo assunto abordava os diferentes tipos de pigmento fotossintetizantes, questionando aos alunos qual era o único capaz de absorver fótons e convertê-los em energia química. A alternativa com maior número de marcações foi a alternativa correta (14 alunos marcaram clorofila), porém 9 marcaram alternativas erradas e 8 alunos não souberam responder. Clorofila não é uma palavra estranha no dia a dia, pois muitas vezes é associada às plantas em meios de comunicação como também é frequentemente mencionada em aulas de ciências ao se tratar de vegetais. Porém, é preciso ressaltar que existe muita confusão com relação à função da clorofila, como: "A clorofila é o sangue das plantas"; "A clorofila atrai a luz solar"; "A clorofila limpa o ar"; "A clorofila é um fortificante" [13]. Assim, os alunos sabem que o pigmento clorofila está relacionado à fotossíntese, mas não compreendem plenamente o que ele faz e porquê é importante.

O oitavo assunto referiu-se às fontes que sustentam a vida no planeta. Essa questão destacou a importância da luz solar como a principal fonte de energia para a vida na Terra uma vez que, através da fotossíntese, inicia-se o fluxo energético na cadeia alimentar, possibilitando a vida de todos os organismos por meio das relações entre os consumidores e decompositores. Onze alunos responderam corretamente, contudo, a maioria dos alunos (19) respondeu que a principal fonte que sustenta a vida no planeta é o oxigênio. Os alunos se concentraram no processo da fotossíntese, e não tiveram uma visão holística e de sua importância para todo o planeta, representando a "especialização", na qual apenas um processo (biológico, físico, químico, bioquímico) é 
considerado e as suas relações com outros processos e com o meio não o são [16]. Isso evidencia que a contextualização do conteúdo está inteiramente ligada ao entendimento correto do mesmo. No caso da fotossíntese, é geralmente explicada de forma especializada, sem relação com ecologia, por exemplo.

O nono assunto abordou a utilização de oxigênio e gás carbônico pelos organismos fotossintéticos. Seis alunos marcaram a alternativa correta $-\mathrm{CO}_{2}$ é absorvido pelos organismos fotossintetizantes e é transformado em matéria orgânica - enquanto vinte assinalaram outras alternativas e cinco não souberam responder. Esse resultado mostra que grande parte dos alunos acredita que o $\mathrm{CO}_{2}$ absorvido é utilizado para a produção de $\mathrm{O}_{2}$, porém $0 \mathrm{O}_{2}$ liberado na atmosfera é proveniente da foto-oxidação da água $\left(2 \mathrm{H}_{2} \mathrm{O}\right.$ à $4 \mathrm{H}^{+}+4 \mathrm{e}^{-}+\mathrm{O}_{2}$ ), além de muitos alunos confundirem fotossíntese com respiração das plantas e filtração do ar. Embora conheçam a equação da fotossíntese e saibam que há liberação de oxigênio, como demonstrado em seus esquemas, não sabem a relação entre reagentes e produtos.

Apresenta-se no Quadro 2 a síntese dos dados referentes aos conceitos centrais das questões do questionário final aplicado após o trabalho com os alunos.

Quadro 2. Dados obtidos no questionário final.

\begin{tabular}{|c|l|c|c|c|}
\hline \multicolumn{2}{|c|}{ Assuntos abordados nas questões sobre fotossíntese } & Acertos & Erros & Não sei \\
\hline 1 & Local onde ocorre cada etapa da fotossíntese & 5 & 16 & 10 \\
\hline 2 & Fase onde ocorre a fixação do carbono & 12 & 17 & 0 \\
\hline 3 & Origem do O I liberado na fotossíntese $^{\prime}$ & 5 & 16 & 8 \\
\hline 4 & Composto orgânico produzido pela fotossíntese & 18 & 8 & 2 \\
\hline 5 & Como ocorre a produção de ATP e NADPH2 & 7 & 14 & 7 \\
\hline 6 & Seres vivos que realizam a fotossíntese & 15 & 12 & 1 \\
\hline 7 & Sequência das etapas da fotossíntese & 12 & 10 & 6 \\
\hline 8 & Organela onde ocorre a fotossíntese & 13 & 12 & 3 \\
\hline 9 & Importância da luz solar para a vida na Terra & 21 & 5 & 2 \\
\hline 10 & Molécula carregadora de elétrons do citocromo ao fotossistema I & 8 & 10 & 10 \\
\hline
\end{tabular}

Em relação ao assunto 1, pode-se observar que a maioria dos alunos (16 erros e 10 não sei) não soube identificar o local em que ocorrem as reações de cada etapa da fotossíntese (membrana do tilacoide e estroma), mesmo estando evidente no modelo didático. Isso revela a importância de reforçar este conceito, bem como o que ocorre em cada etapa.

Em relação ao segundo assunto, a maioria dos alunos (17) também teve dificuldade em assimilar que a fixação do carbono para a produção do composto orgânico ocorre no ciclo de Calvin-Benson (fase bioquímica), que também é dependente da luz. 
Fase fotoquímica e fase bioquímica ocorrem em presença de luz, pois os elétrons precisam ser excitados para dar início à cadeia transportadora de elétrons, assim como a enzima rubisco (ciclo de Calvin-Benson) necessita de luz para ser ativada [20]. É comum nos livros de Ensino Médio ser utilizado termos como "fase clara" ou "fase luminosa" para tratar da fase fotoquímica, e "fase escura" ou "independente da luz" para tratar da fase bioquímica. Estes termos induzem a uma compreensão errônea do assunto, dando a entender que a fixação do carbono ocorre apenas à noite e não depende da luz. Ao contrário, a fotossíntese ocorre apenas de dia. É preciso deixar claro para os alunos que a fixação de carbono ocorre na fase bioquímica, utilizando o poder redutor (NADPH) e ATP da fase fotoquímica, mas que essa fase depende também diretamente da energia solar para a ativação da enzima rubisco. Além disso, é importante que o professor realize constantemente uma análise crítica dos livros didáticos, comparando as informações contidas com outras fontes.

Observou-se que não é evidente para os alunos de onde provém o oxigênio liberado na fotossíntese (assunto 3). Na maioria dos esquemas relacionaram a fotossíntese com a transformação do "ar impuro" em "ar puro" ou a transformação do gás carbônico em oxigênio, conceito que representou $80 \%$ das respostas sobre o que é fotossíntese no trabalho de Zago et al. [19]. Esse conhecimento prévio distorcido, muitas vezes, impede que os alunos assimilem o conhecimento científico, porém é possível que os alunos convivam com fontes de informações errôneas durante o processo de ensino e aprendizagem e aos poucos construam o conhecimento correto, mesmo em paralelo com as antigas crenças, até que, ao longo do tempo, o conhecimento errôneo seja abandonado [16]. Isto foi observado neste trabalho, pois, mesmo mostrando no modelo didático o conhecimento cientificamente aceito de que o oxigênio liberado vem da fotooxidação das moléculas de água, grande parte dos alunos não conseguiu abandonar a concepção anterior. Contudo, este trabalho foi um início e talvez tenham construído outras concepções, mas ainda apontam a concepção que está presente há mais tempo.

Em relação ao quarto assunto do Quadro 2, a maioria dos alunos (18) soube identificar qual o composto orgânico comumente produzido na fotossíntese e a classe à qual pertence (carboidratos), bem como os seres vivos que a realizam (15 acertos assunto 6) e a importância da luz solar para a vida na Terra (21 acertos - assunto 9). É interessante destacar que, antes da apresentação do modelo com explicação do assunto de forma dialogada, a maioria dos alunos não sabia que outros seres, além das plantas, realizavam fotossíntese e também não sabiam exatamente o que era e qual o composto orgânico produzido nesse processo, por considerarem a produção do composto orgânico 
para nutrição do organismo como secundário em relação à liberação de oxigênio. Ficou clara a importância do modelo didático nestas questões, pois contribuiu para facilitar a compreensão dos alunos.

Em relação ao oitavo assunto, observou-se um número aproximado entre acertos e erros/não sei (13-12/3, respectivamente) indicando que parte dos alunos soube responder que a fotossíntese ocorre na organela cloroplasto, dentro da célula vegetal. Embora não seja a maioria, indica um avanço, pois no questionário inicial ficou evidente que os alunos pouco compreendiam sobre o local onde o processo era realizado. Nos esquemas realizados por eles, os alunos apontaram as folhas como local da fotossíntese, assim como descreve outro trabalho [16] e alguns incluíram flores, mas não mencionavam uma organela específica. A partir do contato inicial com o modelo de célula vegetal e posteriormente com a explicação junto ao modelo didático interativo da membrana do tilacoide de um cloroplasto, parte dos alunos conseguiu assimilar que existe uma sede para o processo da fotossíntese. Também foi notável que a maioria dos alunos compreendia a fotossíntese como um processo desvinculado da luz, principalmente a solar, como se fosse um detalhe e não algo essencial. O modelo didático foi útil para evidenciar essa importância, que deve ser vinculada com o conhecimento do dia a dia.

Quanto às questões mais específicas, a maioria dos alunos não acertou (assuntos 5, 7 e 10), conforme mostrado no Quadro 2. Acredita-se que um dos motivos seja a introdução de termos novos para eles e também o pouco tempo de contato com os mesmos. Também, a fase bioquímica foi representada apenas por figuras e esquemas, logo não era interativa e não atraiu tanto a atenção dos alunos, dificultando a aprendizagem. Essas questões envolviam também conceitos de química e, dessa forma, foram mais difíceis para os alunos que, estando no $1^{\circ}$ ano do Ensino Médio, não possuem um conhecimento pleno deles. No trabalho de Bandeira [13], uma das constatações relacionadas à fotossíntese é: "as reações químicas não fazem parte do cotidiano dos alunos". Na verdade, as reações químicas fazem parte do cotidiano, mas muitas vezes esse aspecto não é enfatizado em sala de aula.

\section{Considerações finais}

A fotossíntese é um tema complexo e muitas vezes tratado de forma tão simplificada a ponto de reforçar concepções errôneas dos alunos, como foi verificado neste trabalho. O modelo didático interativo utilizado facilitou o processo de compreensão, uma vez que algo complexo pode ser visualizado em três dimensões. $O$ fato de os íons 
hidrogênio, elétrons e a ATP sintase se moverem, principalmente, chamou a atenção dos alunos e ajudou na compreensão. Assim, o modelo didático tornou o assunto mais próximo do aluno e os processos, abstratos, descritos em livros, fizeram parte de sua realidade, além de despertar curiosidade. Percebeu-se que o número de respostas corretas em relação ao questionário inicial aumentou, e que o número de não sei por resposta diminuiu, o que constitui uma relação positiva com a implementação do modelo didático.

Percebeu-se também que é necessário, antes de introduzir um assunto, partir do conhecimento que o aluno já possui sobre ele. Nesse caso, o questionário inicial (préteste) e os esquemas foram extremamente importantes para saber quais as concepções prévias dos alunos e, assim, quais conceitos científicos enfatizar, a fim de construir o conhecimento correto. Em relação a isso, chamou atenção a variedade de interpretações dos alunos sobre fotossíntese e quão importante é o primeiro "contato científico" dos alunos com o tema na escola, ainda no Ensino Fundamental, porque é a ideia que mais permanece nas suas estruturas cognitivas ao longo de sua vida escolar.

Ressaltamos que a fotossíntese, por sua complexidade, deve ser trabalhada em mais aulas, o que não foi possível neste trabalho uma vez que se tratava apenas de um projeto. Outro ponto a ser considerado é sempre acompanhar o que ainda não está claro para os alunos (neste caso, os alunos não compreenderam muito bem os processos da fase bioquímica), retomar esse assunto e abordá-lo de outra forma. Quanto a isto, vale ressaltar que as questões mais acertadas pelos alunos foram as que estavam relacionadas à parte do modelo que era dinâmica e interativa. Logo, se o modelo for reproduzido, salienta-se que deve ser pensado também em como tornar a fase bioquímica dinâmica da mesma forma que foi realizado na fase fotoquímica.

Esse trabalho também possibilitou aos alunos responsáveis pelo projeto ter contato com a realidade escolar, ainda nos primeiros anos do curso de graduação e verificar aspectos importantes em relação ao processo de ensino e aprendizagem no que se refere ao tema fotossíntese.

Conclui-se, então, que a demonstração prática por meio de modelos, principalmente dinâmicos e interativos, o questionamento, o diálogo, a contextualização dos conteúdos e a relação destes com situações cotidianas, são ferramentas que devem ser exploradas pelo professor, a fim de proporcionar aos alunos uma ampla e plena compreensão do conhecimento científico trabalhado. 


\section{Referências}

[1] Kluge RA. Fotossíntese [apostila]. São Paulo: Universidade de São Paulo; 2008 [acesso em 28 jul 2013]. Disponível em: http://pt.scribd.com/doc/54973120/FOTOSSINTESE-apostila-2008

[2] Prieto A, Mendonça A, Faria J, Batista S. Fotossíntese [trabalho final pré-aula]. Universidade Nova de Lisboa: Faculdade de Ciências e Tecnologia; 2007 [acesso em 18 nov 2013]. Disponível em: https://www.yumpu.com/pt/document/view/12821342/o-mundodas-plantas-a-fotossintese

[3] Medeiros SCS, Costa MFB, Lemos ES. O ensino e a aprendizagem dos temas fotossíntese e respiração: práticas pedagógicas baseadas na aprendizagem significativa. Rev. electrón. enseñ. cienc. [periódicos na internet]. 2009. [acesso em 12 dez 2013]; 8 (3). Disponível em: http://reec.uvigo.es/volumenes/volumen8/ART9_Vol8_N3.pdf

[4] Garcia Pérez FF. Los modelos didácticos como instrumentos de análisis y de intervención em la realidad educativa. Biblio 3W [periódicos na internet]. 2000. [acesso em 10 dez 2013]; 5 (207). Disponível em: http://www.ub.edu/geocrit/b3w-207.htm

[5] Harres JBS, Pizzato MC, Sebastiany AP, Predebon F, Fonseca MC. Laboratórios de Ensino: inovação curricular na formação de professores de ciências. In: $9^{\circ}$ Encontro Gaúcho de Educação Matemática [evento na internet]. 2006 abr 28-30; Caxias do Sul, Brasil [acesso em 10 nov 2013]. Disponível em: http://www.miltonborba.org/CD/Interdisciplinaridade/Encontro_Gaucho_Ed_Matem/postere s/P016.pdf

[6] Predebon F, Del Pino JC. Uma Análise Evolutiva de Modelos Didáticos Associados às Concepções Didáticas de Futuros Professores de Química Envolvidos em um Processo de Intervenção Formativa. IENCI 2009; 14 (2): 237-254.

[7] Matos CHC, Oliveira CRF de, Santos MPF, Ferraz CS. Utilização de Modelos Didáticos no Ensino de Entomologia. Rev. biol. ciên. terra [periódicos na internet]. 2009. [acesso em 17 dez 2013]; 9 (1): 19- 23. Disponível em: http://joaootavio.com.br/bioterra/workspace/uploads/artigos/3matos-51816c32b2719.pdf

[8] Orlando TC, Lima AR, Silva AM da, Fuzissaki CN, Ramos CL, Machado D, Fernandes FF, Lorenzi JCC, Lima MA de, Gardim S, Barbosa VC, Tréz TA. Planejamento, Montagem e Aplicação de Modelos Didáticos para Abordagem de Biologia Celular e Molecular no Ensino Médio por Graduandos de Ciências Biológicas. Rev. Ensino Bioquím. [periódicos na internet]. 2009. [acesso em 9 dez 2013]; (1): 1-17. Disponível em: http://bioquimica.org.br/revista/ojs/index.php/REB/article/view/33

[9] Chrobak R, Benegas ML. Mapas conceptuales y modelos didacticos de professores de química. In: Carlas AJ. Novak JD, editors. Concepts Maps: Theory, Methodology, Technology. Proceedings of the 2nd International Conference on Concept Mapping; 2006 Set 5-8; San José. Costa Rica: Universidade de Costa Rica; 2006. P. 1-8.

[10] Conselho Nacional de Educação (Brasil). Resolução $n^{0}$. 1, de 18 de fevereiro de 2002. Institui Diretrizes Curriculares Nacionais para a Formação de Professores da 
Educação Básica, em nível superior, curso de licenciatura, de graduação plena [resolução na internet]. Diário Oficial da União 9 abr 2002 [acesso em 03 nov 2013]. Disponível em: http://portal.mec.gov.br/cne/arquivos/pdf/CP012002.pdf

[11] Flick U. Introdução à pesquisa qualitativa. 3. ed. Porto Alegre: Bookman; 2009.

[12] Ludke M, André MEDA. Pesquisa em educação: abordagens qualitativas. São Paulo: Editora Pedagógica e Universitária; 1986.

[13] Bandeira CMS. A fotossíntese: estudo das concepções alternativas. São Paulo. Trabalho de conclusão de curso [Graduação de Licenciatura em Ciências Biológicas] Universidade Presbiteriana Mackenzie; 2011.

[14] Souza SC de, Almeida MJPM de. A fotossíntese no Ensino Fundamental: compreendendo as interpretações dos alunos. Ciênc. educ. [periódicos na internet]. 2002. [acesso em 23 out 2013]; 8 (1). Disponível em: http://www.scielo.br/pdf/ciedu/v8n1/08.pdf

[15] Santos CFS. Abordagem metodológica para o ensino de fotossíntese. Cascavel. Dissertação [Programa de Desenvolvimento Educacional em Objeto de Aprendizagem Colaborativa] - Universidade Estadual do Oeste do Paraná; 2008.

[16] Kawasaki CS, Bizzo NMV. Fotossíntese: um tema para o ensino de Ciências? Quím. Nova Esc. [periódicos na internet]. 2000. [acesso em 06 set 2013]; 1 (12). Disponível em: http://qnesc.sbq.org.br/online/qnesc12/v12a06.pdf

[17] Araújo-Jorge TC, Borges EL. A expansão da pós-graduação na Fundação Oswaldo Cruz: contribuições para melhoria da educação científica no Brasil. Rev. Bras. Pós-grad. [periódicos na internet]. 2004. [acesso em 14 set 2013]; 1 (2). Disponível em: http://ojs.rbpg.capes.gov.br/index.php/rbpg/article/download/43/40

[18] Silveira DT, Manzke GR, Manzke VHB, Bobrowski VL. Concepção de célula por alunos egressos do Ensino Fundamental. In: $18^{\circ}$ Congresso de Iniciação Científica. $11^{\circ}$ Encontro de Pós-Graduação. $1^{\circ}$ Mostra Científica [evento na internet]. 2009 out 20-23; Pelotas, Rio Grande do Sul [acesso em 08 nov 2013]. Disponível em: http://www2.ufpel.edu.br/cic/2009/cd/biologicas.html

[19] Zago LM, Gomes AC, Ferreira HA, Soares NS, Gonçalves CA. Fotossíntese: concepções dos alunos do Ensino Médio de Itumbiara-GO e Buriti-Alegre-GO Rev. bras. Biociênc. [nota científica na internet]. 2007. [acesso em 16 nov 2013]; 5 (1): 780- 782. Disponível em: http://www.ufrgs.br/seerbio/ojs/index.php/rbb/article/download/831/660

[20] Kerbauy GB. Fisiologia Vegetal. 2. ed. Rio de Janeiro: Guanabara Koogan; 2012.

\section{Agradecimentos}

Nossos agradecimentos ao colégio, professores e alunos que permitiram a implementação deste projeto. 